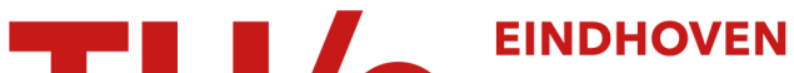 UNIVERSITY OF TECHNOLOGY
}

\section{Engaging senior adults with technology for behavior change}

Citation for published version (APA):

Valk, C. A. L., Lovei, P., Chuang , Y., Lu, Y., Pu, P., \& Visser, T. (2019). Engaging senior adults with technology for behavior change. In Conference Proceedings of Academy for Design Innovation Management (pp. 57-68) https://doi.org/10.33114/adim.2019.05_198

DOI:

10.33114/adim.2019.05_198

Document status and date:

Published: 29/11/2019

\section{Document Version:}

Publisher's PDF, also known as Version of Record (includes final page, issue and volume numbers)

\section{Please check the document version of this publication:}

-A submitted manuscript is the version of the article upon submission and before peer-review. There can be important differences between the submitted version and the official published version of record. People interested in the research are advised to contact the author for the final version of the publication, or visit the $\mathrm{DOI}$ to the publisher's website.

- The final author version and the galley proof are versions of the publication after peer review.

- The final published version features the final layout of the paper including the volume, issue and page numbers.

Link to publication

\section{General rights}

Copyright and moral rights for the publications made accessible in the public portal are retained by the authors and/or other copyright owners and it is a condition of accessing publications that users recognise and abide by the legal requirements associated with these rights.

- Users may download and print one copy of any publication from the public portal for the purpose of private study or research.

- You may not further distribute the material or use it for any profit-making activity or commercial gain

- You may freely distribute the URL identifying the publication in the public portal.

If the publication is distributed under the terms of Article 25fa of the Dutch Copyright Act, indicated by the "Taverne" license above, please follow below link for the End User Agreement:

www.tue.nl/taverne

Take down policy

If you believe that this document breaches copyright please contact us at:

openaccess@tue.nl

providing details and we will investigate your claim. 


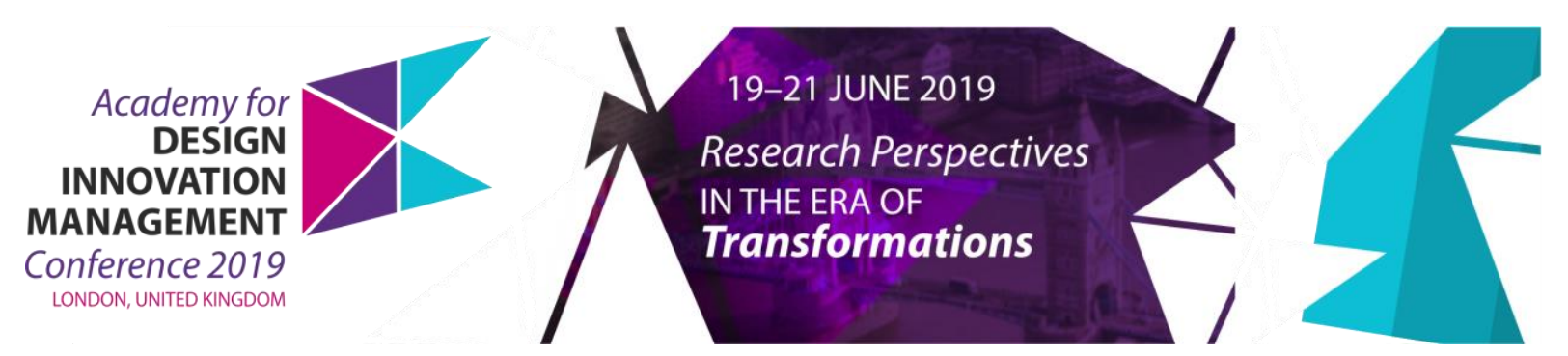

\title{
Engaging Senior Adults with Technology for Behavior Change
}

\author{
VALK Carlijn ${ }^{a *}$; LOVEI Peterb ${ }^{b}$; CHUANG Ya-Liang ${ }^{\mathrm{a}}$; LU Yuan ${ }^{\mathrm{a}}$; PU Pearl ${ }^{\mathrm{d}}$ and VISSER Thomas ${ }^{\mathrm{b}}$ \\ a Eindhoven University of Technology, The Netherlands \\ b Philips Design, The Netherlands \\ d École Polytechnique Fédérale de Lausanne, Switzerland \\ *corresponding author e-mail: c.a.l.valk@tue.nl \\ doi: 10.33114/adim.2019.05.198
}

\begin{abstract}
Amidst today's ever-expanding waistlines there is a clear need to investigate technology's potential to support behavior change and stimulate increased physical activity. Physical activity has also been shown to increase the independence and well-being of older adults, yet an important segment of this community is often excluded from the necessary incontext research due to the barriers they face to technology acceptance. Currently, there is limited knowledge on how to overcome these barriers to participation. We created a specific Product Service System that supports older adults to engage with the proposed technological interventions to enable important in-context behavior change research. Our approach converges knowledge from the domains of living laboratories, co-design, and existing experience of design research with older adults. From our experiences with this Product Service System, we provide guidelines to support other researchers setting-up a living laboratory study with older adults to explore technology's potential to motivate behavior change.
\end{abstract}

Keywords Older adults, Behavior change, Living labs, technology acceptance, Physical activity

\section{Introduction}

The benefits of physical activity are well recognized. According to Bauman et al. (2016), physical activity can not only reduce the risk of chronic disease among older adults but also reverse symptoms of frailty, by, e.g., making physical activity instrumental to fall prevention (Bangsbo et al., 2019; Bauman, Merom, Bull, Buchner, \& Singh, 2016; Chodzko-Zajko, Schwingel, \& Park, 2009; Lopez et al., 2018). Most importantly, physical activity supports older adult's independence and overall quality of life.

The domain of behavior change $(\mathrm{BC})$ focuses on understanding and facilitating the process of changing habits; from current behavior patterns to the adoption of new target behaviors. Personalized BC strategies can be implemented to spark, facilitate or support the process of adopting new habits. Technologies, such as wearable activity trackers and smart phones, have the potential to offer personalized BC solutions to motivate sedentary people to live more actively (Al Ayubi, Parmanto, Branch, \& Ding, 2014; Mitzner et al., 2010; Valenzuela et al., 2018). Research into BC strategies can support a better understanding of how we can take advantage of these new technologies to motivate older adults who could benefit from increased physical activity to adopt a more active lifestyle. However, BC is a dynamic process which is susceptible to changes in time and place or context and thus challenging to investigate without an appropriate approach. Living Laboratories (labs) are valuable methods for in-context research and vital to investigate BC strategies (Eriksson, Niitamo, Oyj, \& Kulkki, 2005; Wu, 2018).

This work is licensed under a Creative Commons Attribution-NonCommercialShare Alike 4.0 International License. https://creativecommons.org/licenses/by-nc-sa/4.0/ 
Though it is clear that older adults have much to gain from the development of technologies which motivate $\mathrm{BC}$ towards a more active lifestyle, there is an important sub-group of older adults who are barred from participating in the necessary in-context research due to their relatively low level of technology acceptance (Anderson, Perrin, Smith, \& Page, 2017; EuroStat, 2019). It is important to enable this group of people to participate in the development of personalized $\mathrm{BC}$ solutions not only because they offer a unique perspective but also be because excluding them from development of these solutions will likely also exclude them from the benefit of these solutions and missing out on the support they need to attain more active, healthy, independent and happy lives. Therefore, researchers should be aware of specific considerations to involve older adults in the living lab research process (Eisma et al., 2004), necessary to investigate how to use BC strategies to support active living.

Initially, our aim was to conduct an in-context investigation, using mobile technologies to compare the effectiveness of two different BC strategies. Though this initial plan yielded interesting results, we found that the setup and execution of this research resulted in insights which would be useful to share with members of the community interested in conducting similar investigations.

In this paper, we report on our study design, setup and execution in order to share how we were able to address barriers to technology acceptance and facilitate an inclusive study to compare BC strategies. To this end, we will present some guidelines to set up a platform to design BC studies for older adults in a living lab context. With knowledge gathered on this topic from various areas of literature, we tailored an existing Product Service System (PSS) to enable BC research in a living lab context with older adult participants. This PSS was implemented to do a research study comparing motivational strategies. A reflection on our implementation of this PSS suggested that a PSS approach to a living lab research study design has potential to overcome the barriers preventing older adults from participating in such researches. The purpose of this paper is to share our reflections on our process to provide inspiration to other practitioners who aim to conduct related studies.

\section{Related Work}

To best position our contribution in this paper, we will discuss certain areas of related work pertaining to the advantages of using a living lab research method for behavior change research, technology acceptance as a barrier many older adults face to participate in these living lab studies and a review of the guidelines other authors suggest to address for this topic.

\section{Research toward the development of behavior change solutions}

Behavior change $(B C)$ is a dynamic process describing the adoption of new habits and routines sometimes in the place of old ones. Due to the dynamic nature of this process it is important to conduct research about BC in the context of use of the intervention. Often the behaviors in question cannot be simulated in a lab environment and nor could the complex web of naturally occurring facilitators and barriers to adoption of the new behaviors. Thus, in-context BC research into how to motivate older adults to live healthy and active lives has become increasingly important, however there are few examples of this kind. Authors Wu Munteanu, 2018, write about a study they did in which they co-created and then field tested a fall risk assessment belt with older adults (Wu \& Munteanu, 2018). However, they report that their five study participants were chosen on convenience and likely do not represent a good cross-section of the very diverse older adult population as all of them had either high or medium familiarity with mobile devices (Wu \& Munteanu, 2018). The use of a living lab in BC research is accepted as a valuable method for the necessary in-context research. The advantage to living lab investigations is that living labs can offer a more realistic view of how an intervention will be used (and possibly misused) in the user's regular day to day context (Hopfgartner et al., 2014). In "Benchmarking News Recommendations in a Living Lab" author Hopfgartner et al. found living lab studies and studies conducted in a laboratory setting had different outcomes. This paper supports the view that living labs can offer a more realistic view of how an intervention will be used in the user's regular day-to-day context. In Hopfgartner's discussion speaks to the "various issues" that need to be addressed in order to do living lab research (Hopfgartner, et al., 2014). The limited examples of studies which do follow up co-design of new technologies with implementation and field testing, might not address but rather avoid barriers like lack of technology acceptance among older adult participants. 


\section{Barriers to research engagement}

The increased availability of smart phones and wearable activity trackers pose intriguing new opportunities for personal health monitoring. In a systematic review of 26 articles about the viability of smartphone use for measuring and influencing physical activity, Bort-Roig et al. found that though these articles reported generally positive accuracy measurements, novel diversity and users' impression of usability, illustrate the potential wearable technologies have to promote physical activity (Bort-Roig, Gilson, Puig-Ribera, Contreras, \& Trost, 2014). Vollmerdahlke and Ory report that mobile applications have already been used for a variety of kinds of health promotion goals including increasing physical activity, to show that mobile technology for health promotion has the potential to be embraced by older adults, however the authors express the need for a better understanding of usability, accessibility, perceived benefit, and relevance to the older adult individuals specific socio-demographics (Vollmer Dahlke \& Ory, 2016). Though, mobile health applications already show potential to support healthy and active ageing, more research is required to adapt these developing technologies to make them appropriate to address the needs of older adults (Helbostad et al., 2017). It is clear that mobile technology's propensity to support BC toward increased physical activity is worth investigating. Moreover, in order to take full advantage of this potential more research needs to be conducted into how we can develop technological solutions, which address the older adult end user in valuable ways.

Despite the clear potential technology offers, there are still barriers to technology acceptance to address. The older adult population is comprised of highly diverse individuals, but there are some important factors that present barriers to a subgroup of older adults preventing them from engaging in design research, which should not go unnoticed nor unaddressed. In particular, the barriers to technology acceptance many older adults experience, present barriers to research engagement (K. Chen \& Chan, 2011; Mitzner et al., 2010; Valenzuela et al., 2018). While $93 \%$ of Europeans aged 25 to 54 reported having used the internet in the last three months, for people aged 55 to 64 this was $73 \%$ and for people aged 65 to 74 this percentage was even lower; $52 \%$ (EuroStat, 2018). Besides a lack of experience with technologies many new technologies do not adequately consider the mental and physical challenges some older adults may face when using this technology, such as decreased dexterity or lack of procedural knowledge (Holzinger, Searle, \& Nischelwitzer, 2007; Vollmer Dahlke \& Ory, 2016). It can be challenging to engage older adults who have limited experience with digital devices to join research studies centered around exploring technology's potential (Eisma et al., 2004; Kopeć, Nielek, \& Wierzbicki, 2018). Though co-designing technological interventions, and in context testing, can support technology acceptance among older adults, barriers exist preventing researchers from taking advantage of these valuable research methods (Binda, Wang, \& Carroll, 2018; Eisma et al., 2004; Harrington, Wilcox, Rogers, \& Connelly, 2018; Holroyd-leduc et al., 2016).

It is vital to overcome the barriers to technology acceptance in order to make research of technologies to support $\mathrm{BC}$ more inclusive, because exclusion from development results in exclusion from these projected benefits. The important challenge which needs to be addressed is; how can we enable older adults with low technology acceptance to engage in research about technologies potential to support $\mathrm{BC}$ ?

\section{Review of existing guidelines}

Experienced authors have already contributed to the body of knowledge of how to set up design research with older adults. Holroyd-Leduc, et al. reported on six points to consider when designing a research study to include older adults with frailty (Holroyd-leduc et al., 2016) while Eisma et al. 2004, provided a more extensive list of recommendations including advice on different methods to obtain information (Eisma et al., 2004). Though it was not our purpose to conduct a literary review, below we share guidelines from some other authors who's work and recommendations inspired our research setup for this investigation.

List of guidelines, which inspired our approach:

- Researchers should be in practical arrangements, adaptable during workshops in accordance with user needs and open to new ways to perceive, define and think about ageing (Binda et al., 2018; Holroyd-Leduc et al., 2016; Malmborg, Werner, Grönvall, Messeter, \& Raben, 2015)

- Researcher should consider the participants specific needs including, but not limited to, impaired visibility (Binda et al., 2018; Holroyd-Leduc et al., 2016) 
- Take the time to facilitate use of technology in context, to understand and respect every day practices, which ad hoc infrastructures constitute a community and what tools can be used in the co-design sessions (Harrington et al., 2018; Malmborg et al., 2015)

- Consider education or training of care providers and researchers on engagement practices (Holroyd-leduc et al., 2016)

- Leverage experience with technology even if gained prior to study (Harrington et al., 2018)

- There may be a need to incentivize participation (Holroyd-leduc et al., 2016)

- Actively engage the older adult participants by breaking the ice, playing games, doing workshops, and find ways to facilitate participants to actively engage with each other (Binda et al., 2018; Harrington et al., 2018)

This body of knowledge describes how to interact with participants and stakeholders during the test, yet provides little clarity on how to design the setup of in-context study of technology intervention toward BC.

In this paper, we describe how we facilitated in-context research to enable older adults with limited technology acceptance overcome barriers to research participation. The purpose of sharing our experiences is to enter the conversation on how to design meaningful products and services which motivate the increased physical activity, with and for older adults.

\section{Initial Study Setup: In-context research to compare BC strategies}

In the REACH Horizon 2020 project case, we aimed to conduct a random control trial to evaluate the effects of two different persuasive strategies on $B C$ through a mobile application with older adults. For this investigation we planned to make two very similar mobile applications one of which would use the BC strategy selfreflection and the other application would use social reflection (these participants would work together with one partnering participant towards a common activity goal). As seen in figure 1, we allowed for a four-week baseline to allow participants to get used to the activity tracker and the smart phone. In workshop two we introduced the intervention applications. After workshop two participants were asked to use the mobile application throughout a period of 5 weeks in their natural home context. In total, 65 older adult participants were recruited via a local senior community center and onboarded in workshop one (figure 1). Of the 58 participants who finished the entire trial period, 43 were female and 15 were male and together their average age was 72.47 and the median age was 73 .

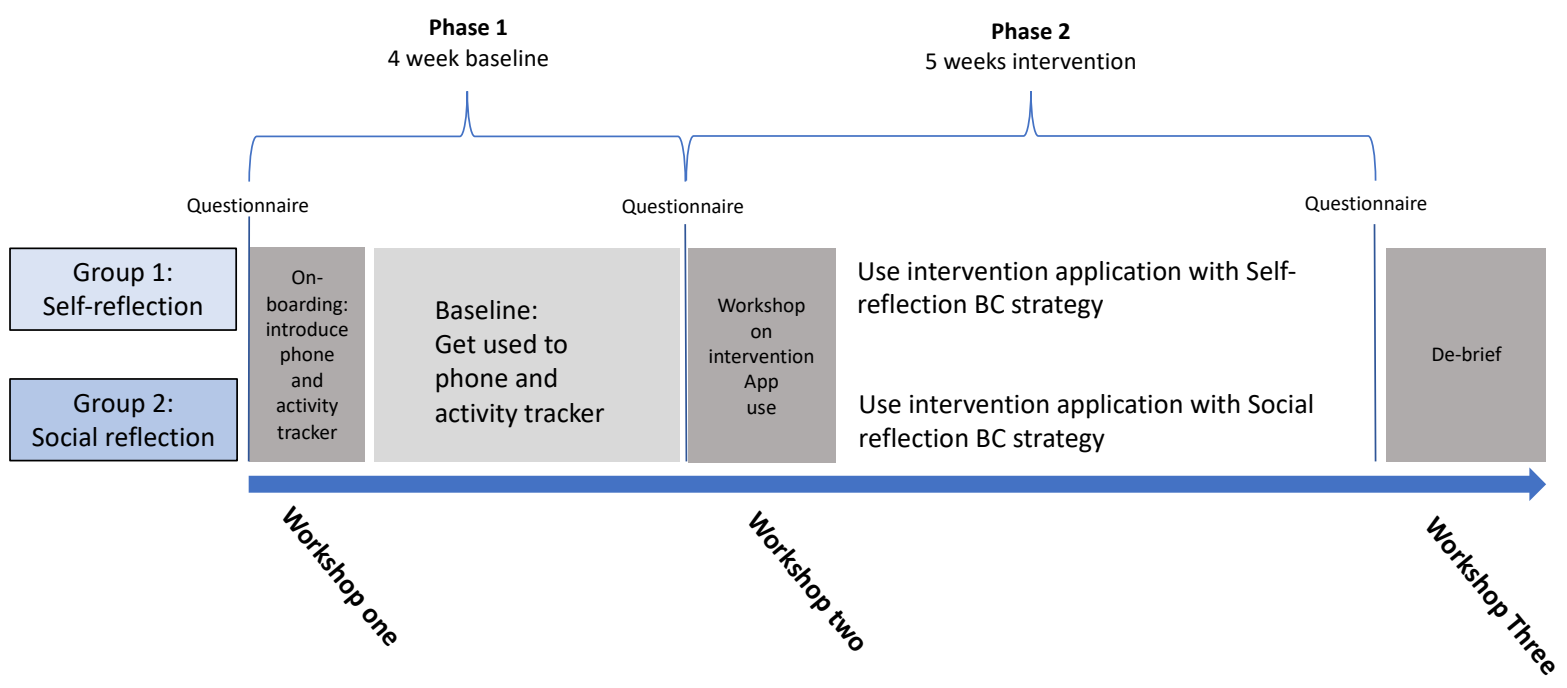

Figure 1. Simple outline of In-context research to compare BC strategies study

Setting up valuable research of this kind requires overcoming barriers to technology so that the interventions in question are acceptable for use to the participants, and collaboration between the stakeholders involved in this context. We aimed to design a study to engage older adults with limited technology acceptance with incontext $\mathrm{BC}$ research. First, we needed to develop the two intervention applications in such a way that these 
were appropriate and usable for participants with limited expertise with technology. Next, we needed to find ways to deliver on-going facilitation to support the in-context use of the intervention applications over the course of study duration.

\section{Results}

The resulting study design aimed to engage older adults with limited technology acceptance with in-context BC research. We overcame barriers to technology in part by re-designing existing test applications through a codesign study with a panel of older adult participants. In order to compare the intervention application incontext we set up a living lab with a local senior community activity center. To deliver on-going facilitation throughout the duration of the study it was necessary for us to take a Product Service System (PSS) approach to the set up and execution of this research study. We used Lee and Kim's, 2010, modified service blueprint to consider the following important aspects of our PSS approach:

- $\quad$ Product and service elements layer refers to the elements that participants interacted with during the entire research study period.

- Service receiver study participant layer refers to activities that the participants undertook during the entire research study period.

- Function interactions layer refers to the activities that the design researchers conducted to create the activities of the participants.

- Onstage service provider activities layer refers to the activities that the living lab volunteers performed to support the on-going research study such as recruiting participating and technological support.

- Backstage service provider activity layer refers to the activities performed by design researchers in supporting the execution of the research study.

- Support processes layer refer to the data storage and management process in the background to support the execution of the research study.

Figure 2 shows how the resulted product service system platform for design research study. In the following, the detailed results per layer are discussed.

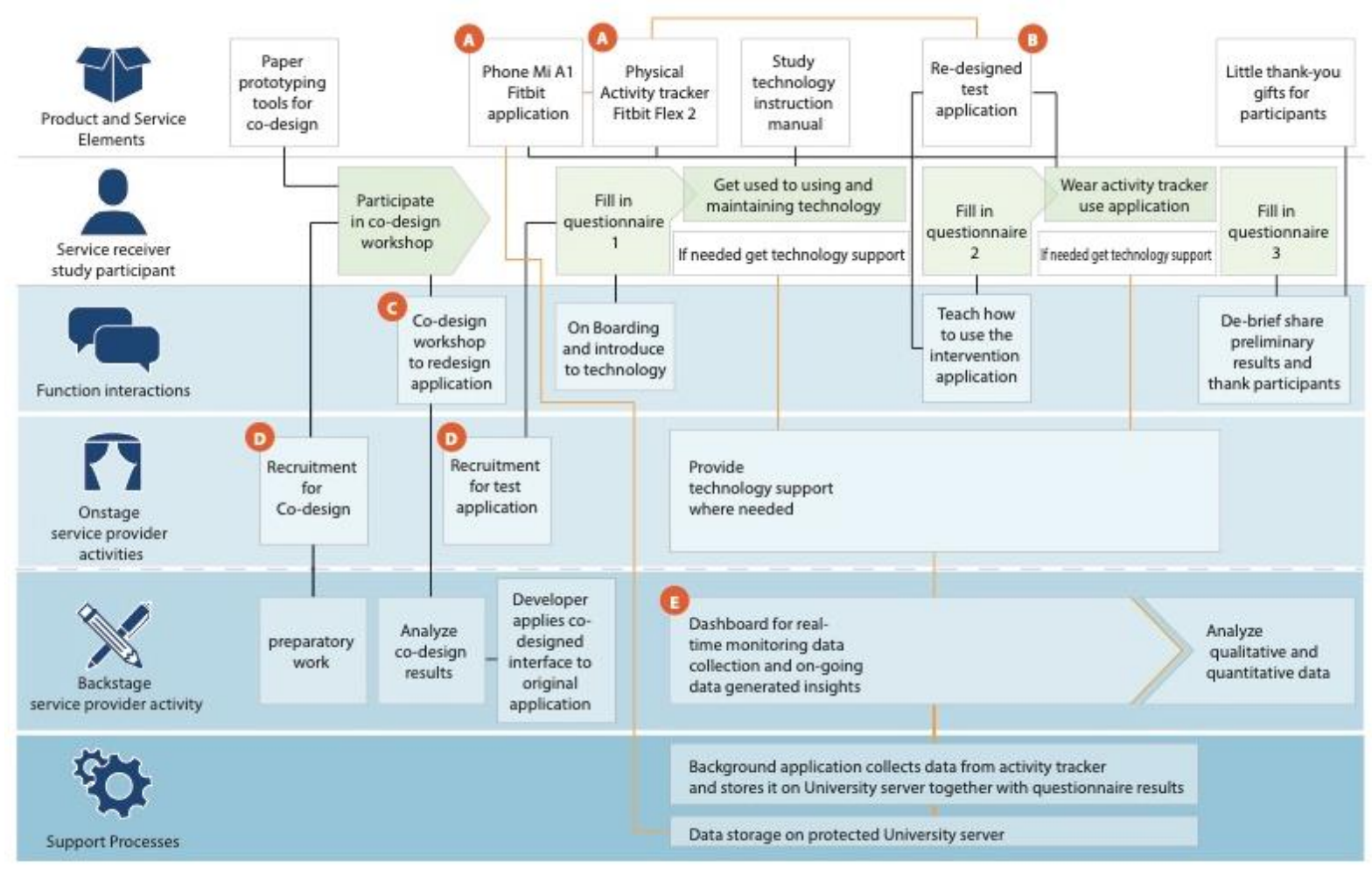

Figure 2. The product service system blueprint enabling living lab investigations to test $B C$ strategies. 


\section{Functions Interactions layer}

In this study, the function interactions can be seen as the main activities of the researchers in creating activities for the participants. It consists of four main activities: Co-design, on boarding, teach how to use the intervention applications and de-briefing. These activities are explained in detail below.

\section{Co-design}

Before the intervention application could be introduced to all the study participants, researchers collaborated with a focus group of five older adults with various degrees of experience with technology to re-design a test application through co-design process, refer to figure $2, \mathrm{C}$. It has been shown that co-designing mobile application with older adults has the potential to yield ideas that are creative and perceived as useful (Davidson \& Jensen, 2013). In addition, Valk et al. (2018) has shown that end-user participating in the design process can contribute to technology acceptance (Valk, Lu, Randriambelonoro, \& Jessen, 2018). This process provided researchers with a better understanding of the accessibility and usability of the technological probes used in this study and to ensure participants had a voice in the design/decision process for this research study. Figure 3 shows some results of the co-design session. This co-design study resulted in the design of the intervention applications used in this investigation, shown in figure 4.

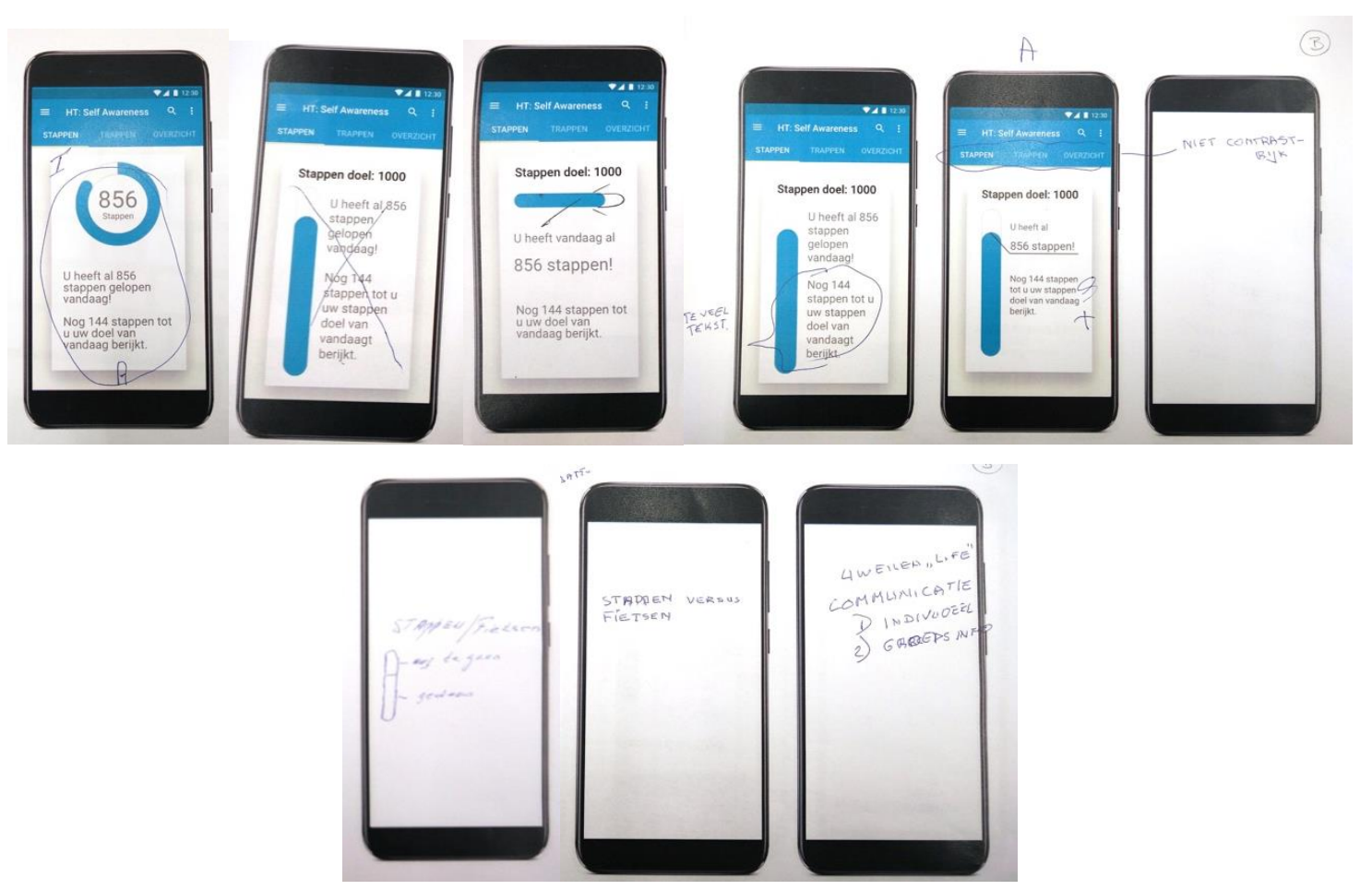

Figure 3. Some results from the application re-design session 


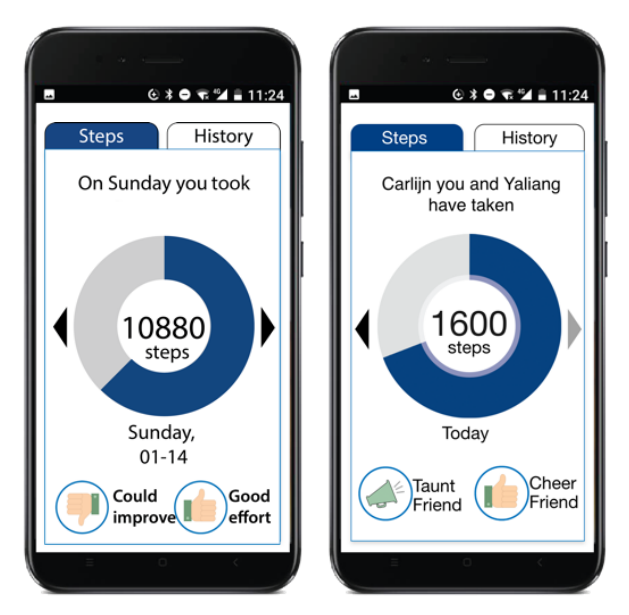

Figure 4. Resulting intervention application for investigation

\section{On-boarding and introduction to technology}

For this living lab study, in addition to regular on-boarding, participants were given a workshop to introduce them to all of the technological elements used in this investigation. In this workshop, researchers guided participants through all the necessary interaction steps of the study's baseline period using the study's custom manual. This thorough introduction was important to make the research inclusive for those with no or very limited prior knowledge on smartphone technology.

\section{Teach how to use the application}

To prevent overwhelming participants who might have limited experience with technology, participants were introduced to the intervention application after the baseline period of the test was done. During this informative session participants received the second chapter of the study specific visual manual and walked through all the functions of the application.

\section{De-brief}

During the De-brief session, participants were surprised with a little token of thanks, and a sneak-peek into preliminary findings made possible by the real time monitoring of the research dashboard. While this session allowed participants to provide useful feedback to researchers which will improve future studies. Most importantly, it was a moment for our research team to express their gratitude to participants and reiterate the importance of their contribution.

\section{Service receiver activity layer}

In this PSS the service receivers were the older adult participants of this living lab research study. Older adult participants were all community dwelling members of a local senior community center. It was advertised that prior experience with a smart phone was not a pre-requisite to participation, in order to recruit participants with various levels of technology acceptance.

\section{Product and service elements layer}

We used several different product and service elements to support the functions of this PSS.

\section{Paper products}

Paper prototyping tools were used during the co-design workshop, to prevent any barriers participating endusers may face using digital prototyping tools from hampering their input. In addition, a detailed visual manual was created, and provided in print, specifically for each condition in this study to support participants who had limited experience with technology. This manual was provided to each participant together with a letter detailing actions required during this study. The letter was included because we acknowledge that many participants might want to talk about their participation with friends and family, and this might facilitate these conversations. 


\section{Hardware elements}

The product and service elements we used for this research study included an off-the-shelf phone, Mi A1, an off-the-shelf wearable activity tracker, Fitbit Flex2, and we tailored an existing probe to test motivational strategies, see figure 2, A. The existing probe was a mobile application initially designed to test motivational strategies by researchers from École Polytechnique Fédérale de Lausanne (Y. Chen \& Pu, 2014), figure 2, B. We redesigned this mobile application, through a co-design session with older adults, figure $2, \mathrm{C}$. While developers implemented changes suggested by the analysis of the results of the co-design re-design session, other members of the research team created detailed visual manuals for the phone and wearable tracker, inspired by the co-design session.

\section{Onstage service provider activity layer}

Existing close positive relationships with a senior community center also partnering in the REACH consortium allowed us to delegate most of the recruitment for the larger study, though researchers did provide flyers clearly explaining the goal of the research, and the expected commitment for participation, figure 2, D.

During the participant on-boarding process, the research team created an open and inviting atmosphere. They explained the study protocol, aim and various privacy security measures that were taken. Researchers often reminded participants of why their contributions are so valuable and worked to show participants their appreciation, by thanking them for their feedback at the end of every session, sharing preliminary insights during a debrief meeting and giving them a small gift as a token of appreciation at the end of the study. We feel the open atmosphere is key to allowing participants to feel comfortable enough to openly share their feedback with us.

\section{Backstage service provider activity layer}

Before testing researchers re-designed and then prototyped an intervention application for testing BC strategies to make this application useable for older adult users through a co-design process. Researchers used a custom developed research dashboard for real-time insight into incoming participant data, figure 2, E. Time was set aside by members of the research team to check the incoming data and reach out to participants who seemed not to be transmitting data regularly. In addition, there was an on-call researcher who participants could call or email if they had questions about the study or use of any of the technologies provided by the research team. If, during these monitoring sessions, we noticed that there was little or no data coming in from a particular participant that participant would be contacted by phone. Usually, any problems could be solved by trouble shooting over the phone but sometimes an in-person meeting was planned to assist participants. This real-time monitoring was instrumental in preventing data loss as many participants needed to be called and helped with relatively simple things such as re-opening the background applications which transmit the physical activity data collection.

\section{Support processes layer}

A background application collected data from the wearable activity tracker in real-time and stored it on a protected server at the Eindhoven University of Technology. Other data from questionnaires provided to the participants was also kept on this protected server, allowing the research dashboard to generate visualization by drawing information from both data sets. The analysis of this data is still ongoing and will be the subject matter of a different paper. In this paper however, we can recommend the use of software which allows researchers to integrate data of different kinds, such as open access weather information, questionnaire data, measured activity data etc. This insight into on-going data collection can be especially valuable to gain insight into the dynamic process of $B C$ in a living lab.

\section{Analysis}

From the use of the PSS described above we can draw some early conclusions about how taking a PSS approach to a living lab investigation increases older adult engagement in important in-context research about $\mathrm{BC}$ toward a more active lifestyle. This promising increase in engagement is evident in how this study supported technology acceptance, this study's low dropout rate and anecdotes collected by the research team. 
In order to support participation, it was necessary to address the barriers to technology acceptance older adults face. In order to do so, the PSS described above, initially called for a co-design session to re-design the intervention application and provided means of on-going technology support. Throughout this investigation, participant's self-reported confidence with mobile smart phone technology improved. Of the 48 participants who responded to this item on all questionnaires, $18.6 \%$ responded that they felt "very confident" about smart phone use to the onboarding questionnaire, while by the debriefing session this percentage had risen to $30.6 \%$.

In addition to the increase in self-reported confidence about technology use, participants showed engagement through their use of the intervention technology presented during this research. Out of the 58 people who participated in this investigation 55 used the messaging (in the social reflection application) or personal log (in the self-reflection application) functions to send messages. Overall a total of 896 messages were sent over the 5 weeks in which the intervention applications were deployed.

Supporting technology acceptance and confidence in smart-phone-use in our method, seemed to lead to increased engagement as we enjoyed a relatively low participant dropout rate during this 9-week study. In this study, the participant drop-out rate from on-boarding till the de-brief session was $11.5 \%$. Other sources describing physical activity promoting research studies with older adults cite drop-out rate between 6 - 36\% (Schmidt, Gruman, King, \& Wolfson, 2000). Though some drop out do to unforeseen or medical reasons in nearly unavoidable, this relatively low participant dropout rate and the overall willingness of participants to continue to participants in the study points to a relatively high level of participant engagement.

Throughout this investigation, participants made ample use of the 'on-call' technology support our team provided. To the researchers this illustrated that participants were concerned with making sure all their devices worked. Participants who reached out for technology support wanted help so they would be able to use the intervention application again. One participant who was unable to fix their problem with guidance over the phone, immediately came over to the university for an in-person meeting, because they did not want to make an appointment and wait to meet the researchers at the senior community center. This showed great motivation to want to take part in the study. At the end of the trial some participants asked if they could download the application and if the hardware was for sale, indicating an interest for continued use. Some participants mentioned talking about their physical activity information displayed in the intervention application and on at least one occasion, participants arranged to meet each other outside of the planned workshops, specially to look at the application together. In this case one participant who was more experienced with technology, took the time to explain it to another participant how the provided mobile devices worked. This anecdotal evidence combined with this study's low participant dropout rate and the indication toward increased technology acceptance, suggest that participants felt engaged in the living lab research about $B C$ strategies.

\section{Discussion and Reflections}

Our living lab research study addresses all of the concerns Hopfgartner et al. mention in their "Benchmarking News Recommendations in a Living Lab", through our implementation of the PSS. Hopfgartner et al., support living labs as a good approach to the evaluation of a product or service, while we use the living lab as a test bed to investigate BC strategies and to develop technologies potential. A living lab is a valuable method however, it is not adequate to overcome the barriers to technology, nor address the needs of older adults with limited technology acceptance.

Though previous work has shown the merits of co-design, living labs, and even presented guidelines for research with older adults, rarely have these domains converged as we propose here. While Liedtke et al. advocate a living lab approach to test product services systems (Liedtke et al., 2015) we advocate a product service system approach to enable living lab research to test BC strategies. Davidson and Jensen, 2013, provide an example of how we can co-design digital interfaces with older adults, yet did not report on developing the proposed ideas into working applications and then testing them in a living lab setting. In their suggestion for future work, they suggest taking the experiment further to the development of the applications (Davidson \& Jensen, 2013), as our PSS approach has allowed us to do here. Implementing the above-described PSS approach to the setup of living lab design research can provide the necessary support to older adult participants, by providing means of on-going engagement. 
The benefit of our PSS is that it has allowed our research team to consider the user experience of being a participant in living lab research. In the past, the use of PSS have been limited to either user testing a PSS (Liedtke et al., 2015) or describing PSS development methodology for business (MOON, OH, KIM, \& HWANG, 2013). Here we advocate for the use of PSS approach to design research.

While our research is still on-going, our reflections on this work so far have yielded guidelines we would like to share:

1) Use a Product Service System approach to set up living lab research

2) Foster relationships to build a living lab community

3) Communicate intentions and expectations ahead of time

4) Co-design necessary interfaces and interventions

5) Show appreciation for their contribution

6) Use best practice policies to ensure privacy and data security

7) Offer tech support

8) Take your time: allow time for questions and for people to get used to the new technologies

9) Facilitate continuous data monitoring

10) Share your findings

Though the preliminary evidence presented here is not conclusive, using the product service approach to create living lab environments for in-context behavior change research shows promise to increase engagement, as indicated by the relatively low participant dropouts and potential to overcome, at least in part, barriers to technology, as demonstrated by this increase in confidence with mobile devices.

\section{Conclusion}

In this paper, we describe the PSS we created to overcome barriers older adults face to participating in living lab research for behavior change. A PSS approach to design research allows us to build on the knowledge from many different research domains which has clear benefits for the research team and participants alike. The PSS we designed enables researchers to engage older adults in living lab research about how technology can support behavior change towards a more active lifestyle, by delivering on-going support to the participants beyond the workshop moments and throughout the several weeks of the study. In our PSS concept, detailed in figure 2, we built on existing guidelines for engaging older adults in research. Like Harrington et al. 2018, we made sure to provide users with relatively limited experience with mobile technologies time to use and get used to the new devices (Harrington et al., 2018). We continued to build a close working relationship with the older adult organization where we conducted our living lab study, in line with the guidelines provided by Eisma et al. (2004) (Eisma et al., 2004). Marin-Hammond et al. (2018) also suggests working with relevant organizations to recruit participants (Martin-Hammond, Vemireddy, \& Rao, 2018). The service provider is an important partner and expert in facilitating this necessary living lab research. Therefore, we would like to encourage other design researchers to follow up the PSS idea by teaming up with expertise outside design field to engage and empower older adults to contribute to behavior change research in living labs.

The purpose of this paper is to share our reflections on our process to provide inspiration to other practitioners who aim to conduct related studies. With this contribution we hope to build a more inclusive research environment to include members of more difficult to access communities toward a better understanding of behavior change strategies.

\section{Acknowledgements}

The authors of this paper would like to thank the REACH Horizon 2020 consortium project as the work presented in this paper was made possible in part by funding from the European Union's Horizon 2020 research and innovation program under grant agreement No 690425. We would also like to extend our gratitude to the men and women who made our contribution possible; the participants and volunteers of the senior community. 


\section{References}

Al Ayubi, S. U., Parmanto, B., Branch, R., \& Ding, D. (2014). A Persuasive and Social mHealth Application for Physical Activity: A Usability and Feasibility Study. JMIR MHealth and UHealth, 2(2), e25. https://doi.org/10.2196/mhealth.2902

Anderson, M., Perrin, A., Smith, A., \& Page, D. (2017). Tech Adoption Climbs Among Older Adults (Vol. 17). https://doi.org/202.419.4372

Bangsbo, J., Blackwell, J., Boraxbekk, C.-J., Caserotti, P., Dela, F., Evans, A. B., ... Viña, J. (2019). Copenhagen Consensus statement 2019: physical activity and ageing. Br J Sports Med, 0, 1-3. https://doi.org/10.1136/bjsports-2018-100451

Bauman, A., Merom, D., Bull, F. C., Buchner, D. M., \& Singh, M. A. F. (2016). Updating the Evidence for Physical Activity : Summative Reviews of the Epidemiological Evidence, Prevalence, and Interventions to Promote “Active Aging ," 56, 268-280. https://doi.org/10.1093/geront/gnw031

Binda, J., Wang, X., \& Carroll, J. M. (2018). Recruiting Older Adults in the Wild : Reflections on Challenges and Lessons Learned from Research Experience. In PervasiveHealth (pp. 2-5). New York: AMC. https://doi.org/10.1145/3240925.3240947

Bort-Roig, J., Gilson, N. D., Puig-Ribera, A., Contreras, R. S., \& Trost, S. G. (2014). Measuring and influencing physical activity with smartphone technology: a systematic review. Sports Medicine (Auckland, N.Z.), 44(5), 671-86. https://doi.org/10.1007/s40279-014-0142-5

Chen, K., \& Chan, A. H. S. (2011). Review A review of technology acceptance by older adults, 10(1). https://doi.org/10.4017/gt.2011.10.01.006.00

Chen, Y., \& Pu, P. (2014). HealthyTogether: Exploring Social Incentives for Mobile Fitness Applications. Proc. of Chinese CHI 2014, (April 2014), 25-34. https://doi.org/10.1145/2592235.2592240

Chodzko-Zajko, W., Schwingel, A., \& Park, C. H. (2009). Successful Aging: The Role of Physical Activity. American Journal of Lifestyle Medicine, 3(1), 20-28. https://doi.org/10.1177/1559827608325456.

Davidson, J. L., \& Jensen, C. (2013). Participatory Design with Older Adults : An Analysis of Creativity in the Design of Mobile Healthcare Applications.

Dell'Era, C., \& Landoni, P. (2014). Living Lab : A Methodology between User-Centred Design and Participatory Design. Creativity and Innovation Management, 23(2), 137-154. Retrieved from https://onlinelibrary.wiley.com/doi/pdf/10.1111/caim.12061

Eisma, R., Dickinson, A., Goodman, J., Syme, A., Tiwari, L., \& Newell, A. F. (2004). Early user involvement in the development of Information Technology-related products for older people. Universal Access in the Information Society, (May 2016), 1-17. https://doi.org/10.1007/s10209-004-0092-z

Eriksson, M., Niitamo, V., Oyj, N., \& Kulkki, S. (2005). State-of-the-art in utilizing Living Labs approach to usercentric ICT innovation - a European approach ., 1(13), 1-13.

EuroStat. (2018). Individuals - Internet use. Retrieved October 15, 2018, from https://ec.europa.eu/eurostat/web/products-datasets/product?code=tin00028

EuroStat. (2019). People in the EU - statistics on an ageing society - Statistics Explained. https://doi.org/ISSN 2443-8219

Harrington, C. N., Wilcox, L., Rogers, W., \& Connelly, K. (2018). Designing Health and Fitness Apps with Older Adults : Examining the Value of Experience-Based Co-Design. In PervasiveHealth (pp. 1-10). New York: Association for Computing Machinery. https://doi.org/10.475/1145_4

Helbostad, J. L., Vereijken, B., Becker, C., Todd, C., Taraldsen, K., Pijnappels, M., ... Mellone, S. (2017). Mobile Health Applications to Promote Active and Healthy Ageing. Sensors (Basel, Switzerland), 17(3). https://doi.org/10.3390/s17030622

Holroyd-Leduc, J., Resin, J., Ashley, L., Barwich, D., Elliott, J., Huras, P., ... Muscedere, J. (2016). Giving voice to older adults living with frailty and their family caregivers: engagement of older adults living with frailty in research, health care decision making, and in health policy. Research Involvement and Engagement, 2(1), 


\section{3. https://doi.org/10.1186/s40900-016-0038-7}

Holroyd-leduc, J., Resin, J., Ashley, L., Barwich, D., Elliott, J., Huras, P., ... Stolee, P. (2016). Giving voice to older adults living with frailty and their family caregivers : engagement of older adults living with frailty in research, health care decision making, and in health policy. Research Involvement and Engagement, 23(2), 1-19. https://doi.org/10.1186/s40900-016-0038-7

Holzinger, A., Searle, G., \& Nischelwitzer, A. (2007). On Some Aspects of Improving Mobile Applications for the Elderly. Universal Access in HCl, Part I, HCII 2007, LNCS 4554, 4554, 923-932. Retrieved from http://skateboardingalice.com/papers/2007_Holzinger.pdf

Hopfgartner, F., Kille, B., Lommatzsch, A., Plumbaum, T., Brodt, T., \& Heintz, T. (2014). Benchmarking News Recommendations in a Living Lab (pp. 250-267). Sheffield: Springer. Retrieved from https://core.ac.uk/download/pdf/42358327.pdf

Kopeć, W., Nielek, R., \& Wierzbicki, A. (2018). Guidelines Towards Better Participation of Older Adults in Software Development Processes using a new SPIRAL Method and Participatory Approach. In 11th International Workshop on Cooperative and Human Aspects of Software Engineering (pp. 49-56). Gothenburg. https://doi.org/10.1145/3195836.3195840

Liedtke, C., Welfens, M. J., Rohn, H., Nordmann, J., Liedtke, C., Welfens, M. J., \& Rohn, H. (2015). LIVING LAB : user-driven innovation for sustainability. Sustainability in Higher Education, 17(4), 106-118. https://doi.org/10.1108/14676371211211809

Lopez, P., Ronei, ·, Pinto, S., Radaelli, R., Rech, A., Grazioli, R., ... Cadore, E. L. (2018). Benefits of resistance training in physically frail elderly: a systematic review. Aging Clinical and Experimental Research, 30, 889-899. https://doi.org/10.1007/s40520-017-0863-z

Malmborg, L., Werner, K., Grönvall, E., Messeter, J., \& Raben, T. (2015). Mobilizing Senior Citizens in Co-Design Work. Proceedings of the 17th International Conference on Human-Computer Interaction with Mobile Devices and Services Adjunct - MobileHCl '15, 916-919. https://doi.org/10.1145/2786567.2794304

Martin-Hammond, A., Vemireddy, S., \& Rao, K. (2018). Engaging Older Adults in the Participatory Design of Intelligent Health Search Tools. In 12th EAI Conference on Pervasive Computing Technologies for Healthcare (pp. 114-123). Brussels: PervasiveHealth. https://doi.org/10.1145/3240925.3240972

Mitzner, T. L., Boron, J. B., Bailey, C., Adams, A. E., Charness, N., Czaja, S. J., ... Sharit, J. (2010). Older adults talk technology : Technology usage and attitudes This text also discribes an example of how to set up research with seniors. Computers in Human Behavior, 26(6), 1710-1721. https://doi.org/10.1016/j.chb.2010.06.020

MOON, S. K., OH, H. S., KIM, S., \& HWANG, J. (2013). A Product-Service System Design Framework Using Objective-Oriented Concepts and Blueprint. In INTERNATIONAL CONFERENCE ON ENGINEERING DESIGN (pp. 1-10). Singapore. Retrieved from https://www.designsociety.org/downloadpublication/34959/A+product-service+system+design+framework+using+objectiveoriented+concepts+and+blueprint

Schmidt, J. A., Gruman, C., King, M. B., \& Wolfson, L. I. (2000). Attrition in an Exercise Intervention: A Comparison of Early and Later Dropouts. Journal of the American Geriatrics Society, 48(8), 952-960. https://doi.org/10.1111/j.1532-5415.2000.tb06894.x

Valenzuela, T., Okubo, Y., Woodbury, A., Lord, S. R., Delbaere, K., Principal, S., \& Delbaere, K. (2018). Systematic Review Adherence to Technology-Based Exercise Programs in Older Adults : A Systematic Review. https://doi.org/10.1519/JPT.0000000000000095

Valk, C., Lu, Y., Randriambelonoro, M., \& Jessen, J. (2018). Designing for technology acceptance of wearable and mobile technologies for senior citizen users. Retrieved from https://pure.tue.nl/ws/portalfiles/portal/122435863/2018_DMI_ADMC_designing_for_Technology_acce ptance_of_wearable_and_mobile_tech_for_senior_users_inculding_funded_by.pdf

Vollmer Dahlke, D., \& Ory, M. (2016). mHealth Applications Use and Potential for Older Adults, Overview of. In Encyclopedia of Geropsychology (pp. 1-9). Singapore: Springer Singapore. https://doi.org/10.1007/978981-287-080-3_289-1 
Wu, A. Y. (2018). Understanding Older Users' Acceptance of Wearable Interfaces for Sensor-based Fall Risk Assessment, 1-13.

Wu, A. Y., \& Munteanu, C. (2018). Understanding Older Users' Acceptance of Wearable Interfaces for Sensorbased Fall Risk Assessment. Proceedings of the 2018 CHI Conference on Human Factors in Computing Systems - CHI '18, 1-13. https://doi.org/10.1145/3173574.3173693 